\title{
RESPON ORANGTUA PRA SEJAHTERA TERHADAP PENAMBAHAN PROGRAM PENDIDIKAN ANAK PADA KejarAURORA
}

\author{
Farida Iriani $^{1}$, Adinda Gladya Puspasari ${ }^{2}$ \\ ${ }^{1}$ PS Agroteknologi Fakultas Pertanian Universitas Bandung Raya, Bandung \\ ${ }^{2}$ Yayasan Kejar Aurora, Bandung
}

farida.iriani52@unbar.ac.id, farida_iriani52@yahoo.co.id, adinda.gladya@gmail.com

\begin{abstract}
Abstrak
Perkembangan teknologi akhir-akhir ini telah banyak mengubah tatanan kehidupan di berbagai aspek. Khususnya di bidang pendidikan, tentang bagaimana nilai-nilai yang diberikan kepada anak, agar dapat menjadikan mereka siap menghadapi tantangan industri global 4.0. Sejak tahun 2012 kegiatan Kelompok Belajar (KejarAURORA) bertujuan untuk mengimplementasikan nilai-nilai inovator khusus bagi anak-anak pra sejahtera di daerah Cihanjuang, kota Cimahi, Jawa Barat. Sejenis kegiatan pendidikan non formal tanpa berbayar telah diterapkan oleh pembina Kejar Aurora, dan berhasil memberikan efek positif bagi anak-anak didik sehingga mampu meningkatkan kemampuan dan sikap percaya diri mereka sebagai cikal bakal inovator di masa depan. Setelah kegiatan berlangsung tujuh tahun, Yayasan Kejar Aurora mengelola kegiatan formal yang terjangkau secara ekonomi bagi anakanak pra sejahtera. Sebagian besar peserta kegiatan merupakan anak-anak yang telah mengikuti kegiatan non formal sebelumnya. Metode penelitian berupa survey dan cara wawancara kepada orang tua yang mendaftarkan anaknya karena sudah mengetahui atau sudah pernah mengikuti kegiatan kejarAURORA sebelumnya. Hasil evaluasi menunjukkan bahwa tingginya tingkat kepercayaan orang tua terhadap kegiatan kejarAURORA merupakan faktor penyebab diterimanya penambahan program pendidikan baru kejarAURORA. Orang tua mempercayakan anaknya untuk mendaftar di program baru kejarAURORA karena ada efek positif perubahan sikap anak, serta pelayanan dan keseriusan kejarAURORA dalam mendidik anak.
\end{abstract}

Kata kunci: Pendidikan, Kejar Aurora, pra sejahtera, non formal, formal 


\section{PENDAHULUAN}

Kebutuhan peningkatan kapasitas sumber daya manusia diperlukan Indonesia untuk mengejar globalisasi. Sebagaimana World Economic Forum memberikan beberapa keterampilan yang perlu dikuasai manusia masa kini agar dapat mengikuti perkembangan. Keterampilan tersebut seperti kehandalan dalam pemecahan masalah yang kompleks, berpikir kritis, kreatifitas, manajemen sumber daya manusia, koordinasi dengan orang lain, kecerdasan emosional, membuat keputusan, orientasi pelayanan, negosiasi, dan fleksibilitas kognitif (WEF, 2016). Menghadapi pertumbuhan sumber daya manusia produktif pada tahun 2050 yang mencapai 70\% (Badan Pusat Statistik, 2010), diperlukan suatu program pendidikan yang mampu mempersiapkan generasi muda menjadi pemimpin di masa depan, pemimpin yang mampu berinovasi untuk menciptakan perubahan lingkungan di sekitarnya.

Pendidikan merupakan salah satu kunci dalam mempersiapkan sumber daya manusia yang siap berinovasi. Para calon inovator ini perlu dididik sejak dini. Pendidikan wirausaha dapat menjadi peran penting untuk melahirkan nilai-nilai yang diperlukan seorang inovator, dengan berfokus pada pengetahuan, keterampilan dan sikap (Chou, 2005 dan Dutta, dkk.,2011). Program pendidikan sebagai upaya untuk mempersiapkan inovator tidak hanya terpaku pada teori saja, melainkan cara berpikir untuk menyelesaikan permasalahan dan siap menjadi agen perubahan. Inovator dapat dipersiapkan sejak dini, sebagaimana Wagner (2012) mengemukakan bahwa inovator dapat ditumbuhkan, diajarkan, dan dibimbing sejak usia dini. Calon inovator harus dibangun keterampilannya seperti rasa keingintahuan, kolaborasi, berpikir asosiatif, dan berani bereksperimen dengan segala resikonya.

Pentingnya membangun calon inovator merupakan tujuan kejarAURORA dalam pelaksanaan kegiatannya. KejarAURORA adalah kelompok belajar yang terfokus pada pengembangan daya imajinasi dan soft skill (kreatvitas, solusi dalam pemecahan masalah, kepemimpinan, kerja sama tim, keterampilan komunikasi, empati, dan lainnya) bagi anakanak berusia 4-18 tahun dengan prioritas berasal dari keluarga pra sejahtera. Kegiatan ini berharap dapat melahirkan inovator bagi diri peserta, lingkungannya maupun negara di masa depan. Kegiatan non-formal sudah dilakukan oleh kejarAURORA selama lebih dari 7 (tujuh) tahun tanpa berbayar. Mulai tahun ajaran 2019, kejarAURORA menambah program pendidikan formal anak setingkat TK.

Filosofi kegiatan kejarAURORA berkonsep pada tiga bagian utama. Pertama adalah belajar dan bermain. Kedua, berimajinasi dan berkarya. Dan terakhir adalah berbahagia bersama-sama. Tiga aspek ini menjadi landasan utama dalam berkegiatan di kejarAURORA (Prabowo dan Ferandy, 2016). Berikut adalah penjelasan filosofi kegiatan pendidikan di kejarAURORA:

Filosofi pertama adalah bermain dan belajar. Belajar melalui cara bermain merupakan kegiatan inti. Bagaimana rasa ingin tahu anak dan mau mencoba hal baru menjadi fokus. Pendekatan belajar dengan bermain memiliki tujuan agar pelajaran menjadi menyenangkan. Harapannya adalah bagaimana peserta bisa belajar dari bermain, bisa bermain sambil belajar, dan belajar cara bermain. Bermain dapat memberikan kebahagiaan bagi peserta dalam menjalani aktivitasnya. Seperti yang ditemukan oleh Paco dan Palinhas (2011) bahwa pendidikan melalui bermain sering dilakukan oleh pendidik yang mengajarkan kewirausahaan. Ketika anak-anak merasakan kebahagian dalam menjalankan kegiatannya, maka akan berkembang kemampuan interaksi dengan orang lain sehingga mampu mencari solusi dalam pemecahan masalah.

Filosofi kedua adalah berimajinasi dan berkarya. KejarAURORA terfokus pada pengembangan daya imajinasi karena percaya bahwa perubahan atau inovasi dimulai dari imajinasi. Kemudian, imajinasi diwujudkan dalam karya-karya yang diciptakan. Di kejarAURORA, anak-anak diberi ruang untuk mengenal potensi diri dengan menstimulasi rasa keingintahuannya. Kemudian, mereka diberikan tempat untuk berimajinasi melalui berbagai media-media sebagai sarana 
eksplorasi imajinasi, diwujudkan dalam bentuk prototipe, dan dapat menceritakan kembali pengalaman diri kepada teman-temannya.

Filosofi ketiga adalah berbahagia bersama-sama. KejarAURORA ingin menciptakan suasana bahagia sebagai fokus utama. Setiap anak diajak beraktivitas selalu diawali dengan rasa bahagia, sehingga dapat menambah semangat dalam berkegiatan. Fokus utamanya adalah berbagi kebahagiaan antar sesama. Selain itu, kebersamaan juga merupakan nilai bagi kejarAURORA karena bukan hanya anak-anak yang menjadi pemangku kepentingan, melainkan orang tua terlibat dalam mengevaluasi kegiatan.

KejarAURORA telah menyusun kurikulum pendidikan non formal sebagai arahan dalam belajar dan bermain dengan anak-anak. Tidak hanya mengacu pada teori, namun juga mempelajari nilai-nilai dari inovator-inovator yang ada saat ini di Indonesia. Kurikulum imajinasi disusun melalui wawancara dengan beberapa tokoh Indonesia dari berbagai usia, jenis kelamin, dan keahlian bidang. Profesi para tokoh diantaranya sebagai CEO, Direktur HR, pengusaha, pemilik sekolah, musisi, seniman dan wirausahawan sosial. Tokoh-tokoh tersebut dipilih berdasarkan keragaman bidang, proses perjalanan mereka dalam membuat karya, dan pengalaman dari kecil hingga dewasa mencapai dunia kerja atau dunia nyata. KejarAURORA mencoba untuk melengkapi keterampilan anak-anak agar meningkat kemampuannya dalam berpikir kritis, kreatifitas, dan inovatif (Prabowo dan Ferandy, 2016).

Nilai-nilai yang ingin ditanamkan dalam berkegiatan di kejarAURORA terfokus pada tiga aspek yaitu sikap, keterampilan, dan pengetahuan (Prabowo dan Ferandy, 2016). Aspek sikap meliputi keimanan, sayang pada keluarga, tanggung jawab, disiplin, percaya diri, toleransi, baik, positif dalam bersikap, daya juang, jujur, inisiatif, empati, bersyukur dan berbagi. Kemudian aspek keterampilan, ada nilai-nilai yang ingin ditanamkan seperti kepemimpinan, kerja sama, komunikasi, kreatif, produktif, dan pemecahan masalah.
Nilai-nilai dari aspek pengetahuan meliputi rasa ingin tahu dan keluasan wawasan.

Materi yang diberikan sesuai dengan tingkat usia, dapat menggunakan materi di sekolah namun dimodifikasi dalam permainan. Anak-anak ditugaskan dalam sebuah proyek untuk menyelesaikan permasalahan. Kegiatan dapat dilakukan secara individu atau kelompok. Porsi terbesar ada pada kegiatan bermain, bereskplorasi hal-hal baru, kegiatan fisik seperti olahraga dan outbond, membuat karya, mempelajari hal-hal yang ada di kehidupan sehari-hari, serta kegiatan penampilan di acara akhir semester. Metode pendidikan adalah umum, seperti menggambar, bermain lego, bermain bebas, membaca buku, membuat karya, mencatat, proyek, presentasi, bertanya, eksplorasi, observasi, dan penampilan (Prabowo dan Ferandy, 2016).

Evaluasi kegiatan kejarAURORA, antara lain para fasilitator melihat perkembangan anak dengan cara observasi, kehadiran, keaktifan, presentasi, portofolio karya, penampilan dan aktifitas anak di buku petualangan. Perkembangan ini juga didiskusikan bersama orang tua sebagai evaluator utama. Secara berkala setiap akhir semester, orang tua memberikan hasil observasinya terhadap perkembangan anakanak. Kegiatan ini merupakan kewajiban karena orang tua yang mengalami perubahan sikap anak setiap harinya. Orang tua dapat memantau kegiatan melalui buku petualangan anak-anaknya. Acara berkumpul dengan orang tua dikemas tidak hanya diskusi namun juga dengan kegiatan lain seperti, belajar memasak, berkebun, bermain, bernyanyi, dan lainnya.

Prabowo dan Iriani (2017) menemukan beberapa perubahan pada anakanak yang mengikuti kegiatan non formal di kejarAURORA. Dari hasil wawancara, mereka merasakan efek positif dan manfaat dari kegiatan bersama teman-temannya di kejarAUROA. Alasannya karena mereka dapat belajar dengan cara yang menyenangkan, dapat bermain beragam permainan, memiliki banyak teman, dan memiliki kegiatan positif.

Selain itu, kepribadian mereka berkembang seiring waktu setelah mengikuti kegiatan. 
Mereka menjadi lebih semangat dalam belajar, rajin membaca, lebih disiplin, dan percaya diri dalam berkomunikasi dengan orang lain. Sedangkan pengaruhnya pada kegiatan di sekolah, mereka merasakan ada perubahan cara bersosialisasi di sekolah, lebih aktif, mudah menyimak pelajaran, dan memiliki daya saing positif untuk menguasai pelajaran.

Mulai tahun ajaran 2019 - 2020, kejarAURORA menambah program pendidikan formal setingkat Taman KanakKanak. Tujuan utama adalah membantu warga sekitar khususnya kelompok pra sejahtera untuk mendapatkan pendidikan formal yang berkualitas, terjangkau secara ekonomi, dan sekaligus memberi dukungan finansial bagi kegiatan non formal tidak berbayar yang selama ini sudah dilaksanakan. Promosi telah disosialisasikan kepada warga sekitar lokasi Taman Belajar kejarAURORA, khususnya kepada orang tua yang telah pernah menitipkan anak-anaknya di kejarAURORA. Para orang tua umumnya (90\%) menyetujui adanya penambahan program pendidikan formal berbayar oleh kejarAURORA sebagai upaya subsidi silang bagi program kegiatan kejarAURORA tanpa berbayar.

Studi ini dilakukan untuk mengevaluasi sejauhmana tingkat kepercayaan orang tua (khususnya kelompok pra sejahtera) kepada kejarAURORA sehingga menyetujui atas penambahan program pendidikan formal berbayar oleh Yayasan Kejar AURORA.

Ada empat poin utama yang ingin diperoleh dalam evaluasi ini yaitu, tentang perubahan sikap anak yang dirasakan oleh orang tua, alasan utama mau mendaftarkan anaknya di pendidikan formal, faktor kepercayaan orang tua kepada kejarAURORA dan harapan orang tua bagi perkembangan kejarAURORA.

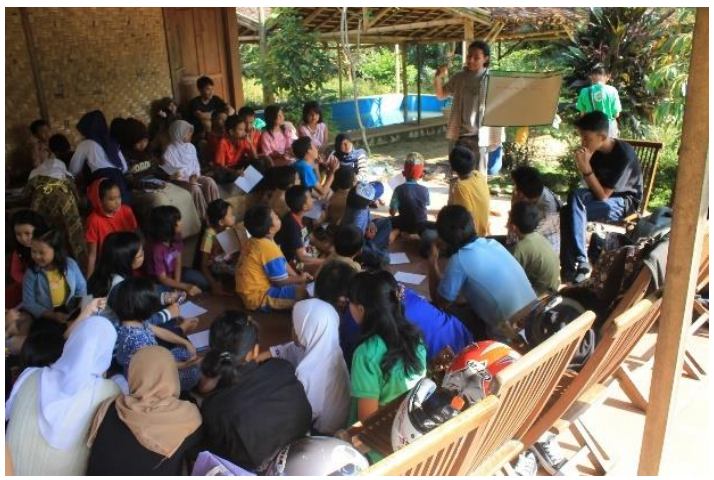

Gambar 1. Kegiatan di kejarAURORA

\section{METODE}

\subsection{Metode Pelaksanaan Kegiatan}

Kegiatan kejarAURORA non formal dilakukan pada setiap hari Sabtu jam 3-5 sore, dan hari Minggu jam 1-4 sore di Taman Belajar kejarAURORA, Jalan Cihanjuang, Rt $03 \mathrm{Rw}$ 11, kelurahan Cibabat Kota Cimahi. Area kegiatan kejarAURORA meliputi dua Rw yaitu Rw 11 dan Rw 20. Anak-anak yang mengikuti kegiatan merupakan warga dari kedua Rw terebut. Ada sekitar 800 KK dari keduanya. Kegiatan ini melibatkan para relawan dan juga pengajar khusus dari kejarAURORA. Para peserta 92\% merupakan anak-anak pra sejahtera. Anak-anak harus mendaftarkan diri terlebih dahulu di awal semester sebagai tanda keikutsertaan. Kegiatan rutin anak-anak selalu didampingi oleh kakakkakak pendamping yang memberikan materi melalui pendekatan bermain sesuai kurikulum. Anak-anak diupayakan untuk berinteraksi dengan anak-anak lainnya dalam setiap kegiatan, seperti membaca, menulis, menggambar, bermain dalam kelompok, membuat karya, olahraga, bernyanyi, menari, dan lain sebagainya.

Kegiatan kejarAURORA melibatkan orang tua didalamnya. Bekerjasama dengan orang tua, kejarAURORA mengkaji perubahan apa saja yang sudah dirasakan orang tua terhadap perilaku positif anak, nilai-nilai apa saja yang sudah berhasil ditanamkan selama masa berkegiatan di kejarAURORA, serta saran dan harapan apa yang diinginkan orang tua terhadap peran kejarAURORA dalam memperbaiki program. Secara berkala dalam satu semester minimal 2-3 kali ada pertemuan 
dengan orang tua. Pertemuan tersebut tidak hanya membahas anak, melainkan juga kejarAURORA memberikan pelatihan kepada orang tua dalam berwirausaha untuk meningkatkan kesejahteraan keluarga, menerapkan metode berbagi dan berbahagia bersama kejarAURORA. Pendekatan belajar sambil bermain juga diberikan kepada orang tua agar mereka mengalami jenis metode belajar yang menyenangkan. Setiap akhir semester orang tua akan diundang untuk melihat penampilan dan karya dari anakanaknya.

Pendidikan formal dilaksanakan di lokasi yang berdekatan (jarak $50 \mathrm{M}$ ) dari lokasi pendidikan non formal. Kegiatan dilaksanakan setiap hari Senin-Jumat jam 8-10 pagi. Raudhatul Athfal (RA) yang dikelola kejarAURORA bertujuan untuk melahirkan insan yang bertauhid, kreatif dan bermanfaat bagi orang banyak. Lokasi RA berada di sebelah musholla yang dibangun oleh Yayasan Kejar Aurora pada awal tahun 2019. Pendidikan disini tidak hanya berlaku untuk anak-anak, tetapi orang tua pun diberi jadwal tersendiri untuk belajar, yaitu pada hari Rabu dan Kamis pagi. Tujuannya selain madrasah yang terbentuk, juga target pengembangan sumber daya manusia bagi orang tua (khususnya orang tua usia muda dari kelompok pra sejahtera).

\subsection{Metode Evaluasi}

Responden terpilih adalah orang tua siswa yang pernah dan atau sedang menitipkan pendidikan anak-anaknya di kejarAURORA baik pada kegiatan non formal maupun formal. Metode evaluasi adalah menggunakan metode survey dan wawancara kepada para responden. Diskusi difokuskan pada empat poin, yaitu perubahan sikap positif anak yang dirasakan oleh orang tua, alasan orang tua mendaftarkan anak pada program pendidikan formal, faktor kepercayaan orang tua dalam memilih pendidikan formal, dan harapan orang tua terhadap perkembangan program pendidikan kejarAURORA. Tujuan evaluasi ini adalah untuk mengkaji lebih lanjut tentang seberapa besar peran kejarAURORA terhadap pendidikan anak pra sejahtera tanpa berbayar serta bagaimana respon orang tua pra sejahtera terhadap penambahan program pendidikan formal yang dilakukan oleh kejarAURORA secara berbayar.

\section{HASIL DAN PEMBAHASAN}

\subsection{Data}

Data yang telah dikumpulkan terdiri atas 25 responden, merupakan orang tua pra sejahtera yang memiliki anak usia 4-6 tahun. Dengan spesifikasi 20 responden pernah menitipkan pendidikan non formal anak pada kejarAURORA, sedangkan 18 responden merupakan orang tua dari peserta didik program pendidikan formal, sedangkan sisanya adalah responden orang tua yang belum pernah menitipkan anak di pendidikan non formal kejarAURORA . Data responden disajikan pada Tabel 1.

Tabel 1. Data orang tua pra sejahtera yang Memiliki anak usia 4-6tahun

\begin{tabular}{|c|c|c|c|}
\hline & Jenis responden & $\begin{array}{l}\text { Jumlah } \\
\text { responden }\end{array}$ & $\begin{array}{c}\% \text { setuju } \\
\text { program baru }\end{array}$ \\
\hline 1. & $\begin{array}{l}\text { Ortu anak didik } \\
\text { non formal pada } \\
\text { kejarAURORA }\end{array}$ & 20 & 88 \\
\hline 2. & $\begin{array}{l}\text { Ortu anak didik } \\
\text { formal pada } \\
\text { kejarAURORA }\end{array}$ & 18 & 100 \\
\hline 3. & $\begin{array}{l}\text { Ortu anak didik } \\
\text { non formal dan } \\
\text { formal pada } \\
\text { kejarAURORA }\end{array}$ & 13 & 100 \\
\hline 4. & $\begin{array}{l}\text { Ortu bukan anak } \\
\text { didik non formal } \\
\text { hanya anak didik } \\
\text { formal } \\
\text { kejarAURORA }\end{array}$ & 5 & 100 \\
\hline & Total responden & 25 & 97 \\
\hline
\end{tabular}

Ada 7 responden dari 20 responden orang tua dari anak didik kejarAURORA non formal yang tidak meneruskan pendidikan formal di RA kejarAURORA. Dua responden tidak memberikan alasan, sedangkan 5 responden menyatakan bahwa sudah terlanjur mendaftarkan anaknya terlebih dahulu pada pendidikan formal lain.

\subsection{Hasil Evaluasi Orang Tua}


Ada empat poin utama dalam penelusuran evaluasi hasil dari kegiatan pendidikan non formal di kejarAURORA terhadap orang tua. Berikut ini penjelasan keempat poin tersebut:

Poin pertama adalah perubahan apa saja yang dirasakan oleh orang tua pada anakanaknya setelah mengikuti kegiatan kejarAURORA. Disini orang tua berperan sebagai evaluator perkembangan anaknya dengan memperhatikan efek positif dari kegiatan di kejarAURORA. Orang tua memperhatikan nilai-nilai apa saja yang tertanam pada anak, misalnya sikap baik apa yang bertambah, keterampilan apa saja yang terasah, dan pengetahuan apa saja yang berkembang. Aspek sikap yang berkembang pada anak-anak yang dirasakan orang tua seperti memiliki sikap hormat dan patuh kepada pada orang tua, bertanggung jawab, dapat bersosialisasi dengan teman, toleransi, percaya diri, mandiri, rajin dan mau belajar. Pada aspek keterampilan, anak-anak sudah mulai memiliki kemampuan untuk bekerjasama dengan orang lain, mau berbagi, dan terlatih kreatifitasnya serta berani berekspresi. Pada aspek pengetahuan, anakanak mulai mengembangkan rasa keingintahuan, seperti apa yang dipelajari di kejarAURORA mereka akan lanjutkan di rumah. Seiring dengan itu, berkembang pula ilmu pengetahuan anak seperti kemampuan berhitung, membaca, menulis dan pemahaman tentang hal-hal dalam norma hidup keseharian.

Poin kedua adalah mengenai alasan orang tua dalam mendaftarkan anaknya di pendidikan formal yang dikelola oleh kejarAURORA. Berdasarkan hasil survey, faktor utama orang tua dalam mempertimbangkan dan memilihkan sekolah formal untuk anak, yaitu kepercayaan dari orang tua terhadap kejarAURORA, lokasi yang dekat dari rumah, serta biaya sekolah yang terjangkau. Dengan sudah mengenal program pendidikan di kejarAURORA dan lingkungan sekitar membuat orang tua nyaman untuk mendaftarkan anak-anaknya.

Terdapat beberapa TK di lingkungan sekitar lokasi Taman Belajar kejarAURORA yang masih berada di lingkungan Rw 11 dan
Rw 20 kelurahan Cibabat, kota Cimahi. Namun salah satu pertimbangan mengapa memilih pendidikan formal di kejarAURORA adalah faktor keamanan lingkungan karena anak-anak harus menyebrangi jalan raya. Sehingga lokasi RA yang dikelola kejarAURORA menjadi pilihan karena akses lebih aman dan mudah dicapai dari rumah orang tua. Berikut ini komentar dari orang tua, "Karena jarak sekolah yang dekat tidak perlu menyebrang jalan raya dan sudah kenal juga dengan kakak-kakak Aurora, jadi percaya." dan " tidak khawatir akan kehandalan kakakkakak dalam membimbing anak-anak."

Tarif pendidikan juga menjadi salah satu pertimbangan orang tua, karena kejarAURORA menawarkan pembiayaan yang sangat terjangkau dibandingkan TK di sekitar, pembayaran yang bisa dicicil, dan beasiswa bagi anak yatim. Berikut ini adalah komentar dari salah satu orang tua siswa, "Karena biaya sekolah yang tidak terlalu mahal, dan jarakrumah ke sekolah mudah dijangkau dan selain itu yakin kualitasnya akan baik karena dikelola oleh Aurora."

Poin ketiga yaitu alasan utama orang tua percaya pada kejarAURORA karena telah merasakan efek positif dari perubahan sikap anakselama mengikuti kegiatan. Ada juga yang merasakan perubahan dari sikap tetangga dan saudaranya yang pernah mengikuti pendidikan di kejarAURORA. Rasa percaya terhadap kualitas kakak-kakak pendamping merupakan komentar yang paling banyak diutarakan oleh responden (890\%). Salah satu komentar dari orang tua, "Yang membuat percaya karena kakak-kakak Aurora memberikan bukti bukan janji, memberikan motivasi yang menumbuhkan sikap dan akhlak terpuji bagi anak-anak agar menjadi lebih baik dan lebih berhati-hati dalam bergaul, serta mengajarkan bagaimana kita menjadi seseorang yang sukses, memotivasi untuk mengejar cita-cita serta menghargai dan berbagi dengan sesama."

Pendekatan dan sikap lemah lembut yang ditampilkan oleh kakak-kakak pendamping di kejarAURORA terhadap anak- 
anak didik mendapatkan respon positif $98 \%$ dari orang tua yang menjadi responden. Dimulai dari pendekatan terhadap anak, mengajarkan anak untuk belajar dengan cara bermain, serta memberikan fasilitas kepada anak untuk mengeksplorasi rasa keingintahuannya. Pelayanan dan pendekatan kakak-kakak pendamping dengan orang tua juga meningkatkan persentase rasa percaya orang tua terhadap kualitas pendidikan (89\%). Dengan demikian respon orang tua dalam memilih program pendidikan anak, sangat didukung oleh kualitas pendidik, fasilitas belajar dan perubahan sikap positif anak setelah mengikuti program pendidikan.

Poin keempat adalah harapan dari orang tua terhadap penambahan program pendidikan anak di kejarAURORA, antara lain agar kejarAURORA terus berupaya meningkatkan inovasi di bidang pendidikan, mampu memotivasi anak dan orang tua agar setia mengikuti perkembangan program pendidikan di kejarAURORA, serta pengelola terus bersemangat untuk mengembangkan sarana dan pra sarana kejarAURORA sehingga jumlah peserta didik semakin bertambah dari tahun ke tahun.

Harapan dari orang tua menjadi landasan kejarAURORA untuk mengevaluasi diri atas segala kekurangan, mengembangkan kurikulum sesuai standar kemendikbud bahkan melampaui, dan terus berinovasi dalam menciptakan program-program pendidikan baru untuk menyesuaikan perkembangan zaman industri 4.0.

\section{KESIMPULAN}

Kegiatan pendidikan non formal bagi anak-anak pra sejahtera yang dilaksanakan kejarAURORA selama lebih dari 7 tahun, telah memberi efek positif terhadap perubahan sikap atau perilaku peserta didik, yaitu anakanak pra sejahtera, sehingga menunmbuhkan kepercayaan yang tinggi bagi para orang tua untuk melanjutkan menitipkan pendidikan anak melalui kejarAURORA. Berbagai kegiatan yang dilakukan oleh kejarAURORA terfokus pada kegiatan belajar melalui bermain, sehingga para peserta didik memperoleh pembelajaran yang menyenangkan. Nilai-nilai innovator yang ingin ditanamkan dapat tersampaikan melalui berbagai kegiatan. Hasil studi menunjukkan bahwa para orang tua pra sejahtera yang memiliki anak usia 4-6 tahun menyetujui (98\%) adanya penambahan program pendidikan formal di kejarAURORA karena mereka telah merasakan efek positif yang nyata dari kegiatan non formal di kejarAURORA sebelumnya. Adanya penambahan biaya atas terbentuknya program pendidikan formal, bukanlah masalah bagi mereka mengingat tarif pendidikan yang terjangkau, biaya dapat dicicil, tersedia beasiswa bagi anak yatim, serta meumbuhkan semangat berbagi dengan sesama.

KejarAURORA telah mampu membuka wawasan dan hati nurani para orang tua pra sejahtera dalam mengembangkan pengelolaan kegiatan pendidikan formal berbayar sebagai upaya subsidi silang dari kegiatan pendidikan non formal tanpa bayar yang dilaksanakan oleh kejarAURORA.

Kepercayaan orang tua terbangun dari hasil didikan kakak pembimbing terhadap perkembangan positif perilaku anak dan bertambahnya pengetahuan anak setelah mengikuti pendidikan non formal di kejarAURORA. Kepercayaan orang tua juga diiringi dengan berbagai harapan agar kejarAURORA terus konsisten berinovasi dalam mendidik anak-anak pra sejahtera agar kelak mampu berkompetisi di era industri 4.0.

\section{UCAPAN TERIMA KASIH}

Terima kasih kepada pengelola Yayasan Kejar Aurora, para donator tidak tetap, guru, kakak pembimbing, para orang tua dan anak-anak didik kejarAURORA yang telah berpartisipasi dalam pelatihan dan pendidikan selama ini dalam rangka untuk mengembangan sumber daya manusia di masa depan

\section{REFERENSI}


Badan Pusat Statistik, (2010). Piramida Penduduk Indonesia, [Online], Available:http://sp2010.bps.go.id/

Chou, C.M. (2005). Entrepreneurship education promoting commercial education students' employments. MinDao Journal, Vol. 1 No. 1, p 15-30

Dutta, D. K., Li, J., and Merenda, M. (2011). Fostering entrepreneurship: impact of specialization and diversity in education. International Entrepreneurship Management Journal, 7, 163-179.

Paco, A and Palinhas, MJ. (2011). Teaching entrepreneurship to children: a case study. Journal of Vocational Education and Training Vol. 63, No. 4, December 2011, 593-608

Prabowo, P dan Ferandy, M (2016).

KejarAURORA: Belajar, Bermain, Berimajinasi, Berkarya, Berbahagia, Bersama. Cimahi: kejarAURORA

Prabowo, P dan Iriani, F (2017). Implementasi Nilai Inovator KejarAURORA Bagi AnakAnak Pra Sejahtera. Jurnal Pengabdian Kepada Masyarakat Universitas Islam Nusantara, Bandung. Vol. 7 No.1

Wagner, Tony (2012). Creating Innovators: The Making of Young People Who Will Change the World. New York: Scribner.

World Economic Forum, (2016). WEF Future of Jobs. [Online] Available: http://www3.weforum.org/docs/WEF_ Future of Jobs.pdf 